\title{
Design of a Low Cost Remotely Operated Vehicle with 3 DoF Navigation
}

\author{
Romi Wiryadinata*1, Annisa Sucianti Nurliany ${ }^{2}$, Imamul Muttakin ${ }^{3}$, Teguh Firmansyah ${ }^{4}$ \\ Electrical Engineering Dept., Universitas Sultan Ageng Tirtayasa \\ Jl. Jend. Sudirman km 03, Cilegon-Banten, Indonesia, 42435, Fax/Phone: 0254-395502 \\ ${ }^{*}$ Corresponding author, e-mail: wiryadinata@untirta.ac.id ${ }^{1}$, a.sucianti.n@gmail.com², \\ imamul@untirta.ac.id ${ }^{3}$, teguhfirmansyah@untirta.ac.id ${ }^{4}$
}

\begin{abstract}
One type of underwater robot is the ROV (Remotely Operated Vehicle) whose movements are controlled directly by humans from the water surface. In this paper, ROV prototype has been designed and tested with three DoF (Degrees of Freedom) and controlled by a joystick which is connected with UTP (Unshielded Twisted Pair) cables as data transmission between joystick with a microcontroller embedded in the robot. This prototype has 3 thrusters with 3 degrees of freedom, 1 rotational motion (heave) and 2 translational motion (yaw and surge), with direction of movement up, down, forward, backward, turn right, and turn left. Speed mode setting when forward movement on PWM (Pulse Width Modulation) 75\%0,037 $\mathrm{m} / \mathrm{s}, 90 \% 0.053 \mathrm{~m} / \mathrm{s}$ and $100 \% 0,071 \mathrm{~m} / \mathrm{s}$, while the reverse speed by $75 \% 0,034 \mathrm{~m} / \mathrm{s}, 90 \% 0.045 \mathrm{~m} / \mathrm{s}$ and $100 \% 0.059 \mathrm{~m} / \mathrm{s}$, when the ROV moves up is $0,042 \mathrm{~m} / \mathrm{s}$, down $0.032 \mathrm{~m} / \mathrm{s}$, turn right $9 \%$ and turn left $15 \%$ set with fixed PWM value, is $100 \%$.
\end{abstract}

Keywords: underwater robot, remotely operated vehicle, ROV control

\section{Introduction}

Based on control systems, underwater robots are divided into two types of AUV (Autonomous Underwater Vehicles) and ROV (Remotely Operated Vehicles). AUV is underwater vehicle capable of moving in the water automatically without direct human control [1]. While the ROV is underwater vehicle whose movements are controlled directly by humans from the water surface [2].

Generally ROV is known as mini-submarines that commonly used in the oil and gas industry offshore. ROV is equipped with specific sensors such as camera or video [3], transponder, compass, odometer, bathy (data depth) and others depending on the purposes and objectives of its usage [4-5].

The design of a vehicle is a prolonged process that consists mainly of three design phases which are the conceptual design, the preliminary design, and the detailed design [6]. In designing the ROV, there are several different configurations, but there are some things that must be considered including mechanical design for operating in water and electronic devices. ROV should be able to move in three dimensions. At least, ROV has 3 pieces thrusters, 1 thruster to adjust the depth and 2 thrusters to regulate the movement direction of the ROV. Besides, the size and weight should also be taken into account because it can affect the performance of ROV [7].

\section{Research Method}

The hardware used in this study comprises mechanical devices with the main material robot frame is made of PVC pipe which is easily obtainable materials. The electronic component consists of a minimum system microcontroller ATMega32, $\mathrm{H}$-bridge mosfet motor driver, joystick PS (Play Station) [8-10], and three DC motors. Software used to create the PCB design is Proteus, the software used to create the mechanical design is SolidWorks, while the software used as compiler is CodeVision AVR. Block Diagram of ROV control system can be viewed as shown in Figure 1. 


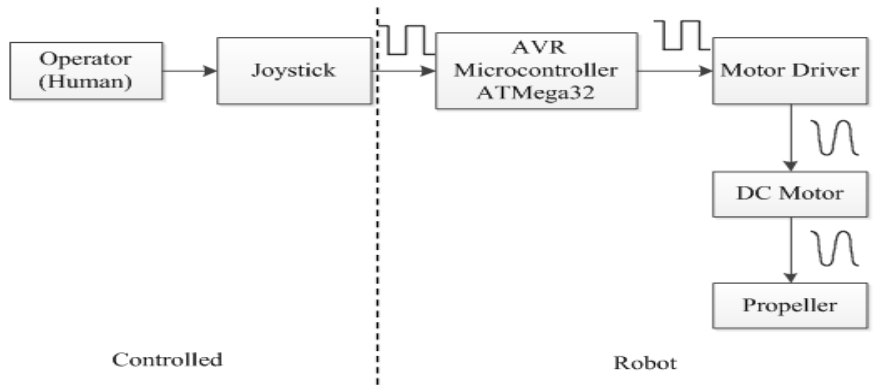

Figure 1. Block diagram of ROV control system

On Figure 1, PS joystick provides input signals to a microcontroller to read and altered data to the movement. The data has been processed by a microcontroller will be sent to the motor driver to drive a DC motor.

\section{ROV Design}

ROV is required to have the following characteristics:

a. Minimal tether diameter (for instance, a single strand of unshielded optical fiber).

b. Powered from the surface having unlimited endurance (as opposed to battery operated with limited power available).

c. Very small in size (to work around and within structures).

d. Have an extremely high data pipeline for sensor throughput.

Any vehicle has movement about six degrees of freedom, three translations (surge, heave, and sway along the longitudinal, vertical, and transverse (lateral) axes respectively) and three rotations (roll, yaw, and pitch about these same respective axes) [11-12]. Vehicle degree of freedom is shown in Figure 2.

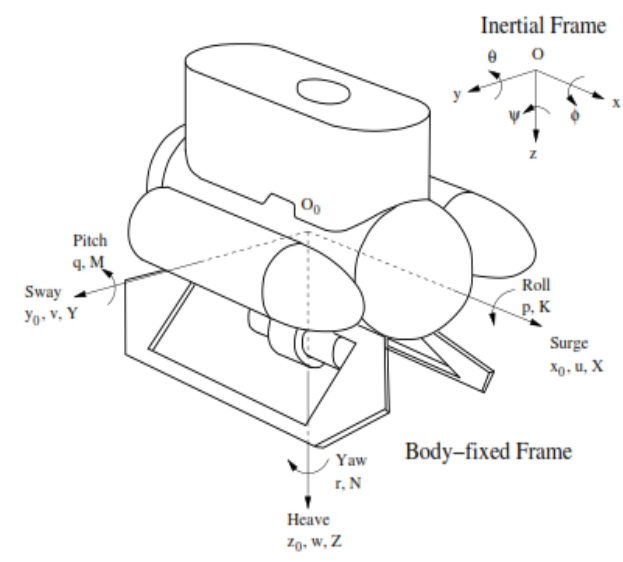

Figure 2. Vehicle degree of freedom [13]

Archimedes' principle states: an object immersed in a fluid experiences a buoyant force that is equal in magnitude to the force of gravity on the displaced fluid. Thus, the objective of underwater vehicle flotation systems is to counteract the negative buoyancy effect of heavierthan-water materials on the submersible (frame, pressure housings, etc.) with lighter-than-water materials; hence a near neutrally buoyant state is the goal. The flotation foam should maintain its form and resistance to water pressure at the anticipated operating depth. Hydrostatic equilibrium of ROV is shown in Figure 3. 
The resultant of all of the weight forces on this displaced fluid is centered at a point within the body termed the Center of Gravity (COG). This is the sum of all the gravitational forces acting upon the body by gravity. The resultant of the buoyant forces countering the gravitational pull acting upward through the COG of the displaced fluid is termed the Center of Buoyancy (COB). COG and COB on ROV are shown in Figure 4.

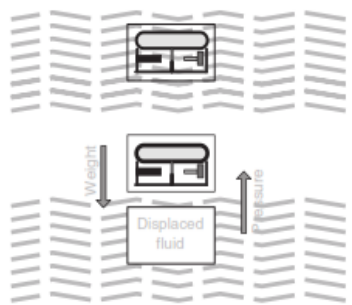

Figure 3. Hydrostatic Equilibrium of ROV [13]

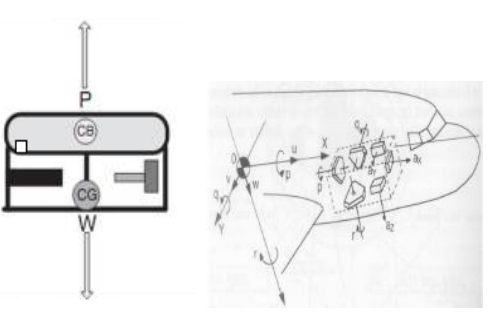

Figure 4. COG-COB Orientation on Vehicle [12-13]

\subsection{Mechanic}

Mechanics made in this study consisted of several parts. Hull robot is a robot frame which is made using 4-inch PVC pipe. Hull robot becomes the main support of all the components that are used by the robot. PVC pipe fitting on the hull using pipe adhesives and adhesive silicon gel. Components and materials used in robots can be seen in Table 1.

Table 1. Components and Materials

\begin{tabular}{llcccc}
\hline \multirow{2}{*}{ Component Name } & \multirow{2}{*}{ Materials } & \multicolumn{4}{c}{ Dimension $(\mathrm{mm})$} \\
\cline { 3 - 6 } & PVC pipe & 340 & - & - & liameter \\
\hline Hull robot & PVC pipe & 130 & - & - & 48 \\
Motor casing & Aluminium & - & - & 5 & 5 \\
Bearing & Plastic & - & - & 10 & 48 \\
Propeller & Plastic & 20 & - & - & 108 \\
electrical cover & PVC dop & - & - & 20 & 114 \\
Hull cover & Aluminium & 40 & - & - & 5 \\
Shaft & Brass & 18 & - & 8 & 6 \\
Coupling shaft & PVC pipe fitting & - & - & - & $85 \times 60$ \\
Propeller cover (right \& left) & Plastic container & 160 & 80 & 85 & - \\
Propeller cover (upper hull) & PVC pipe T fitting & - & - & - & 48 \\
Connection right and left side hull & PVC & & & &
\end{tabular}

Note: (-) means not having unit of dimension

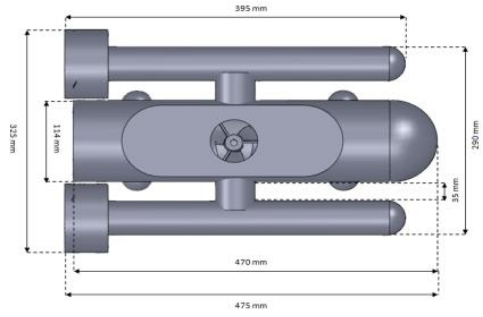

(a)

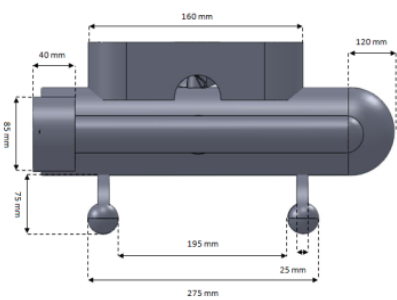

(b)

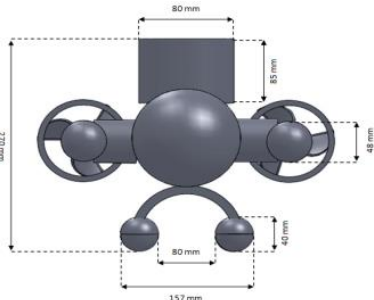

(c)

Figure 5. ROV design; (a) Top view, (b) Side view, (c) Front view

This ROV using 3 DC motors, as the thrusters, with 1 thruster for the degrees of freedom heave and 2 thrusters mover for degrees of freedom yaw and surge. Overall ROV has dimensions of length $475 \mathrm{~mm}$, width $325 \mathrm{~mm}$, height $270 \mathrm{~mm}$ and weighs $8.5 \mathrm{~kg}$. Design results can be seen in the ROV device in Figure 6. 


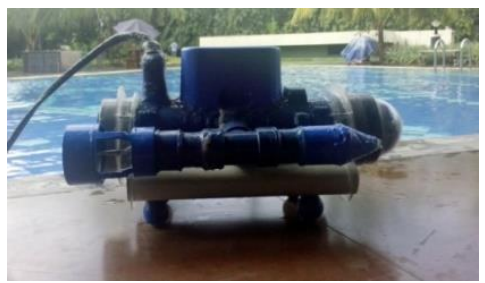

Figure 6. ROV device

Hull robot is used as a center for the whole buffer ROV components, that is for placement of electronic circuits, a DC motor casing, foot, cover the hull and ballast. To connect components on a ROV mechanical component, several kinds of materials are used, including pipe glue, epoxy glue, glue silicon rubber and resins. There are some parts of the mechanical components that are connected permanent and non-permanent. Electronic components used in this ROV is not directly placed inside the hull. To minimize the entry of water, the hull front and back cover was given in advance before being closed by the cover hull, as can be seen in Figure 7.

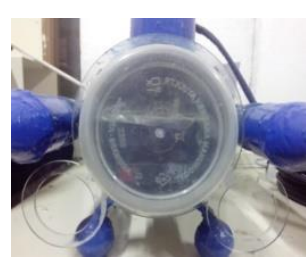

(a)

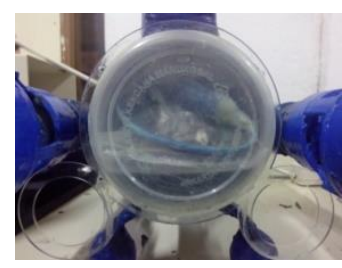

(b)

Figure 7. The placement of the circuit board; (a) The front of the circuit board, (b) The back of the circuit board

ROV position can be seen as an initial condition ROV into the water were placed in a floating position (below the waterline). Testing the neutral position is performed several times until finding the neutral position corresponding to the ROV. It was first performed by the test of ROV weight of $3,452 \mathrm{~kg}$ was obtained when the ROV is in float condition. These conditions require ROV ballast in order to achieve a neutral position. Some testing are done by adding ballast load to get a neutral position with a total weight of ROV to $8.5 \mathrm{~kg}$. The test results last neutral position can be shown in Figure 8.

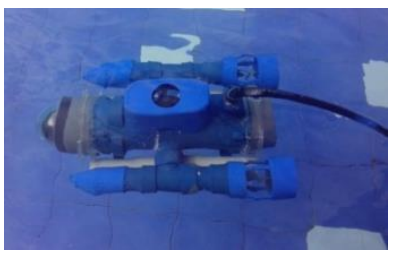

Figure 8. ROV neutral position

\subsection{Electrical}

Electrical design in this research is divided into several functional parts that are interrelated. The main controller is a joystick liaison PS to translate keystrokes and as the central driver of the ROV. DC motor driver is used as a DC motor controller which is used as a driver ROV.

Motor driver using a series of $\mathrm{H}$-bridge MOSFET in Figure 9. Mosfet used for motor driver in this study is IRF9530 and IRF530. Transistors used are of low voltage and medium voltage power 2N3904 NPN type. Series of logic gates used is IC HCF4011BE to minimize the use of pins and to provide a signal ON/OFF given by microcontroller on the motor driver. 


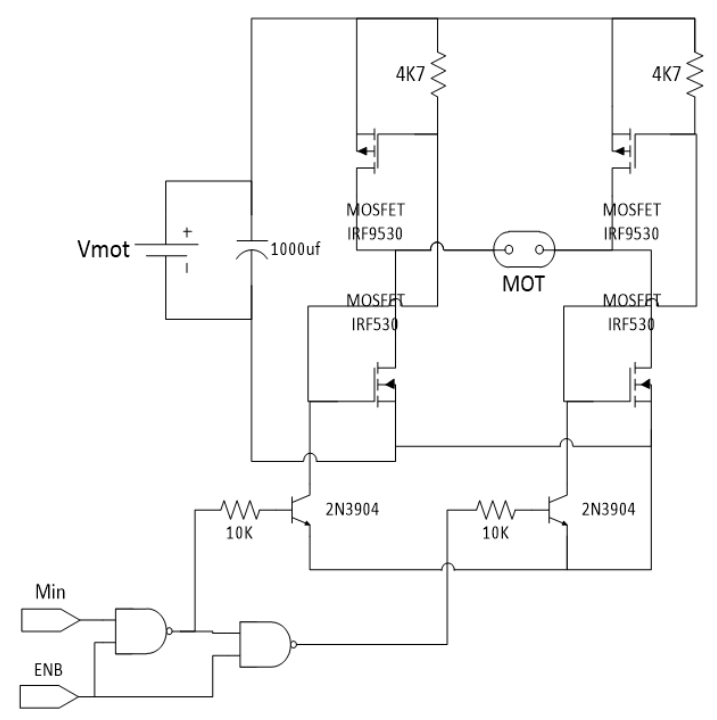

Figure 9. Mosfet $\mathrm{H}$-bridge motor driver circuit diagram

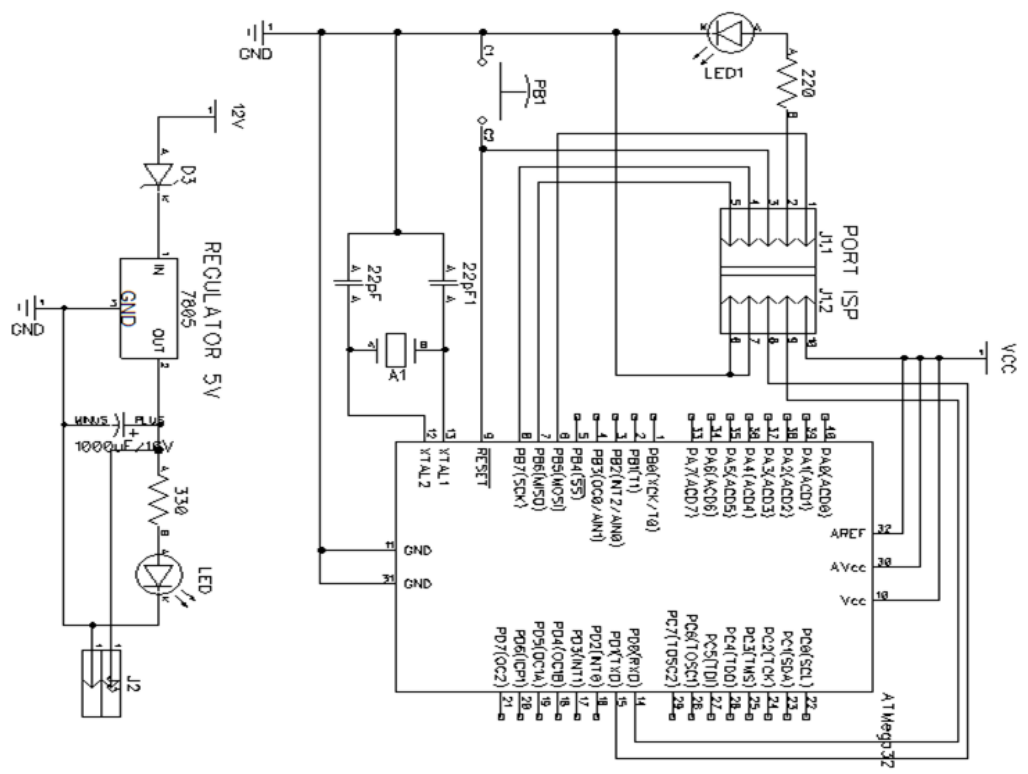

Figure 10. Main controller circuit diagram

Microcontroller used as the main controller ROV is the AVR microcontroller family, namely ATMega32. In the circuit of main controller Figure 10, there are several series including the minimum configuration of the system, ISP ports, and $5 \mathrm{~V}$ regulator.

Board electronics on the ROV is divided into two, that are the main controller and $\mathrm{H}$ bridge motor driver mosfet. On the main controller board, there is ATMega32 microcontroller circuit and the connecting circuit PS joystick. On board electronics, the connecting cable is used to connect between the main controller with $\mathrm{H}$-Bridge motor driver mosfet that is shown in Figure 11. 


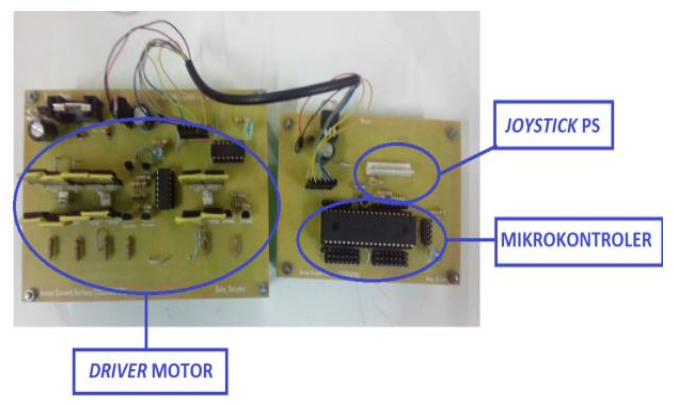

Figure 11. Main controller board dan motor driver

\subsection{PWM (Pulse Width Modulation)}

PWM frequency value generated by the microcontroller is equal to $5859 \mathrm{~Hz}$ which can be obtained from the calculation PWM mode using equation (1).

$$
f_{O C_{n} P W M}=\frac{f_{c l k} I / O}{N \times 256}
$$

PWM Frequency on a timer / counter timer/counter $f_{O C_{n} P W M}$ with units $(\mathrm{Hz})$ obtained by frequency values clock $f_{c l k I / O}$ is a value crystal used, $N$ variable is presented the prescaling factor $(1,8,64,256$, or 1024$)$.

Calculation the value of PWM $75 \%, 90 \%$ and $100 \%$ are done by using the same calculation using equation (2).

$$
v_{o}=\text { Duty Cycle } \times v_{i}
$$

PWM Duty Cycle is a value that can be described in units of percentage (\%). This value is the result of the multiplication percent from the comparison period when high voltages are marked with th (s) and time of maximum PWM ie T or the sum of the current time of high and low voltage $t_{h}+t_{l}$ with time unit (s). PWM output voltage $V_{o}$ with the unit voltage (V) (equation 2) can be obtained by multiplying the percentage of PWM to the input voltage $V_{o}$ the unit voltage (V) [13]. The overall results of manual calculations PWM value can be seen in Table 2.

\begin{tabular}{|c|c|c|}
\hline $\begin{array}{l}\text { PWM } \\
(\%)\end{array}$ & $\begin{array}{c}\text { Microcontroller } \\
\text { voltage }(\mathrm{V})\end{array}$ & $\begin{array}{c}\text { Motor } \\
\text { Voltage }(\mathrm{V})\end{array}$ \\
\hline 75 & 3.75 & 9 \\
\hline 90 & 4.5 & 10.8 \\
\hline 100 & 5 & 12 \\
\hline
\end{tabular}

Table 2. Result Manual Equation

Other than through calculation, also conducted are tests to measure the results of the response to the PWM output voltage value using a digital multimeter. Results can be seen in Table 3.

Table 3: Teset Result PWM Response

\begin{tabular}{ccccc}
\hline PWM & Microcontroller & \multicolumn{3}{c}{ Motor Voltage $(\mathrm{V})$} \\
$(\%)$ & voltage $(\mathrm{V})$ & Mot1 & Mot2 & Mot3 \\
\hline 75 & 3.75 & - & 7.5 & 7.7 \\
90 & 4.48 & - & 9.4 & 9.5 \\
100 & 4.97 & 12.1 & 12.1 & 12.1 \\
\hline
\end{tabular}

Speed DC motor setting on the ROV using 3 PWM value, is $75 \%, 90 \%$ and $100 \%$. The highest value of $100 \%$ derived from measurement to produce a motor voltage in accordance

Bulletin of EEI Vol. 6, No. 1, March 2017: $13-23$ 
with voltage $12 \mathrm{~V} \mathrm{DC}$ motor is used. PWM signal is generated when the duty cycle of $75 \%, 90 \%$ and $100 \%$ of the pin microcontroller and motor driver in a sequence as shown in Figure 12, Figure 13 and Figure 14.

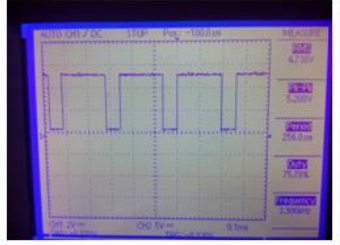

(a)

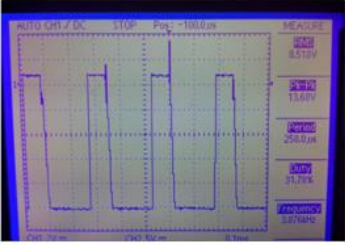

(b)

Figure 12. Voltage signal microcontroller and the motor voltage when PWM $75 \%$, (a) the voltage microcontroller signal, (b) the motor voltage signal

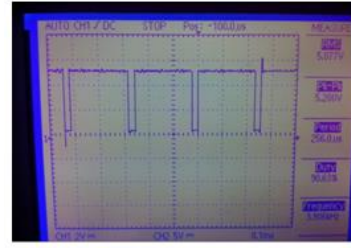

(a)

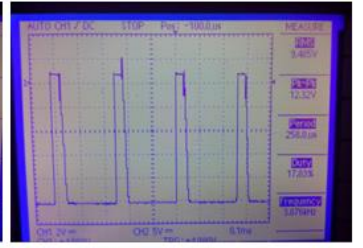

(b)

Figure 13. Voltage signal microcontroller and the motor voltage when PWM 90\%, (a) the voltage microcontroller signal, (b) the motor voltage signal

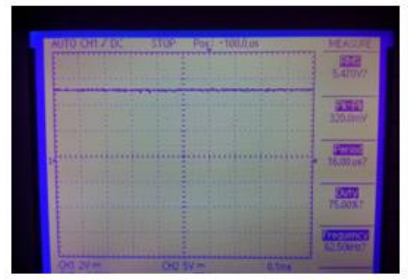

(a)

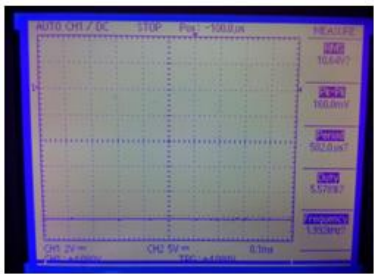

(b)

Figure 14. Voltage signal microcontroller and the motor voltage when PWM $100 \%$, (a) the voltage microcontroller signal, (b) the motor voltage signal

\subsection{ROV Speed}

ROV speed testing was done by measuring the time when the ROV moves to achieve a certain distance. Results of the speed of each movement of the ROV as it moves up and down, turn right and turn left, and back and forth in a sequence can be seen in Table 4, Table 5 and Table 6.

Table 4. Speed Moves up and down

\begin{tabular}{ccccc}
\hline ROV Movements & Distance $(\mathrm{m})$ & $\begin{array}{c}\text { PWM } \\
(\%)\end{array}$ & $\begin{array}{c}\text { Time } \\
(\mathrm{s})\end{array}$ & $\begin{array}{c}\text { Speed } \\
(\mathrm{m} / \mathrm{s})\end{array}$ \\
\hline Down & 0.9 & 100 & 34 & 0.032 \\
Up & 0.9 & 100 & 28 & 0.042 \\
\hline
\end{tabular}


Tabel 5. Speed Turn Right and Turn Left

\begin{tabular}{ccccc}
\hline ROV Movements & Distance $\left({ }^{\circ}\right)$ & $\begin{array}{c}\text { PWM } \\
(\%)\end{array}$ & $\begin{array}{c}\text { Time } \\
(\mathrm{s})\end{array}$ & $\begin{array}{c}\text { Speed } \\
(\% / \mathrm{s})\end{array}$ \\
\hline Turn Right & 45 & 100 & 5 & 9 \\
Turn Left & 45 & 100 & 3 & 15 \\
\hline
\end{tabular}

Table 6. Speed Forward and Backward

\begin{tabular}{ccccc}
\hline ROV Movements & Distance $(\mathrm{m})$ & PWM $(\%)$ & Time $(\mathrm{s})$ & Speed $(\mathrm{m} / \mathrm{s})$ \\
\hline \multirow{3}{*}{ Forward } & 1 & 75 & 27 & 0.037 \\
& 1 & 90 & 19 & 0.053 \\
& 1 & 100 & 14 & 0.071 \\
Backward & 1 & 75 & 29 & 0.034 \\
& 1 & 90 & 22 & 0.045 \\
& 1 & 100 & 17 & 0.059 \\
\hline
\end{tabular}

\subsection{Control System and Program}

ROV control system in designing this using a PS (Play Station) joystick. PS joystick has 16 buttons and 4 analog lines. In this study a UTP cable is used to connect PS joystick with microcontroller. Controlling devices is shown in Figure 15.

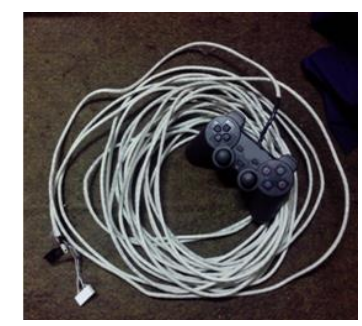

Figure 15. Controlling device

Not all buttons on the joystick PS are being used, DC motor speed setting on the ROV is made with three modes, that is low, medium, and high. This ROV equipped with LED lights. To turn on and off the LED. For functions that use the movements button, speed settings button, and certain sequence has been set on the button is shown in Figure 16.

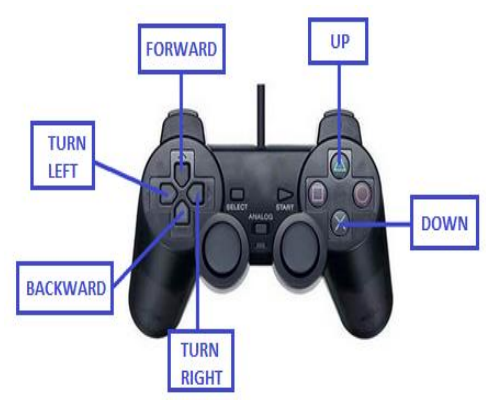

(a)

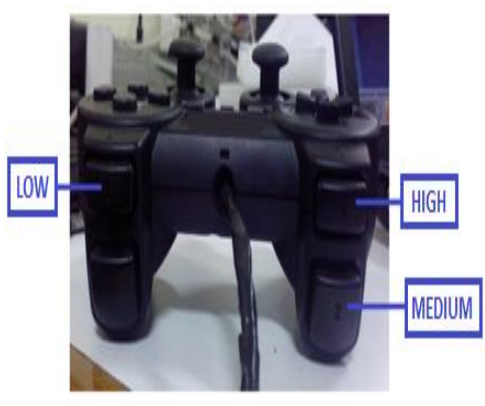

(b)

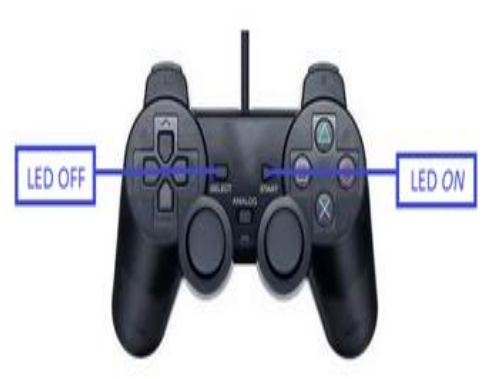

(c)

Figure 16. Function controlling device, (a) function movements button, (b) function speed settings button, (c) function ON/OFF the LED button

The design of the robot program consists of readings made from joystick PS, the movement of the ROV, and speed setting of a DC motor using PWM. When the power supply is 
ON, the program began clicking joystick initialization. Flowchart of ROV systems in this study is shown in Figure 17.

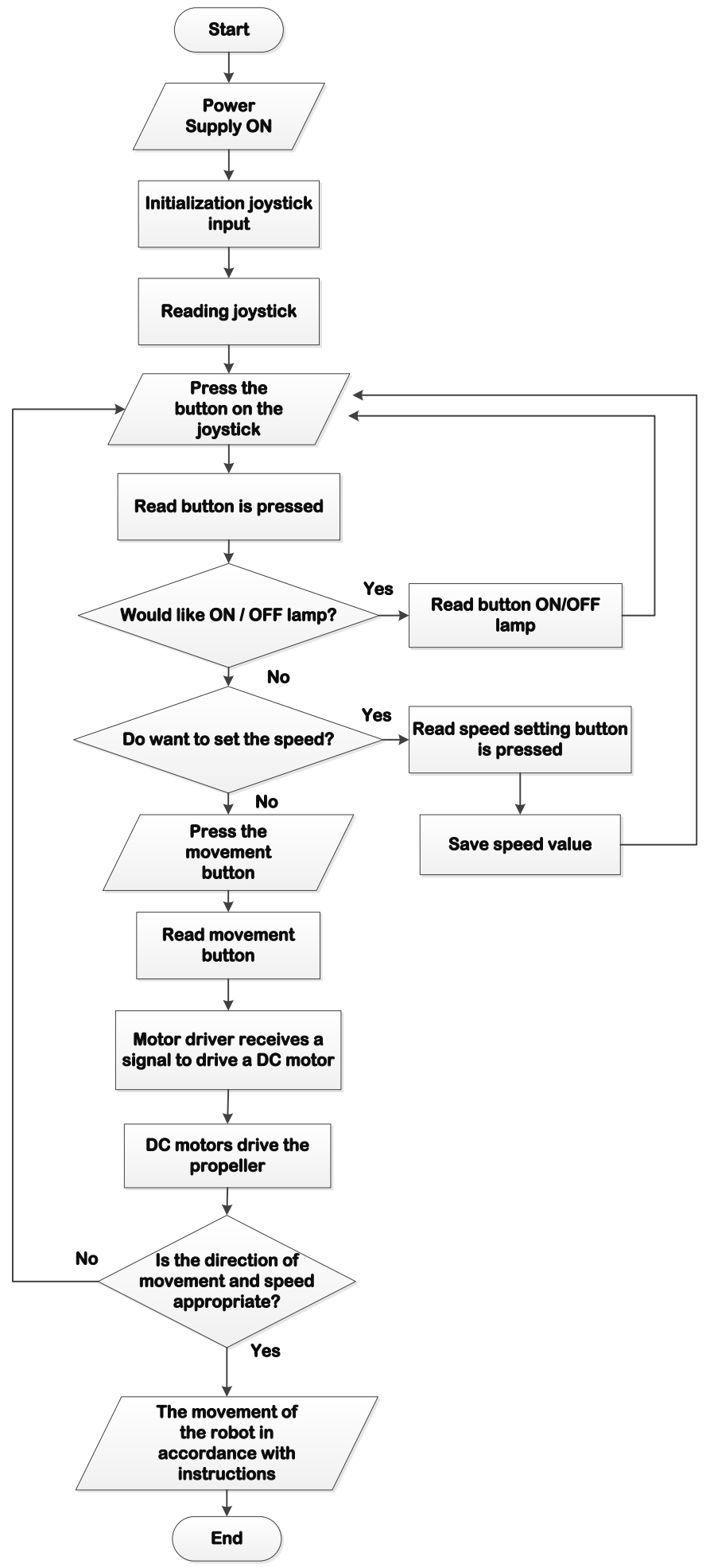

Figure 17. ROV system flowchart 
ROV in this study using three DC motors that generate 7 directions of movement. The movement of ROV based buttons on the joystick can be seen in Table 7 .

Table 7. Movement of ROV Based Buttons

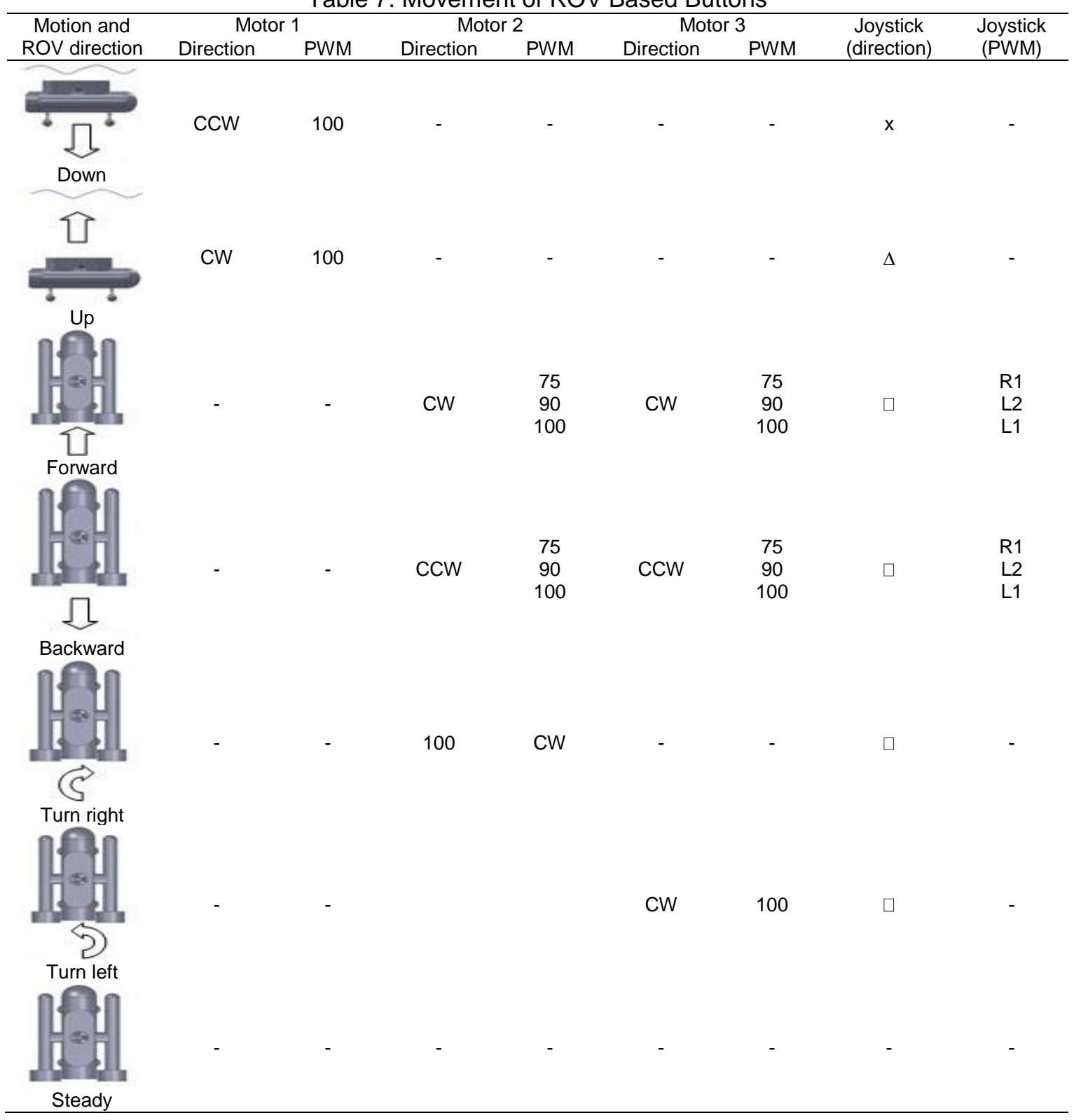

\section{Conclusion}

The research has designed a prototype of ROV using 3 DC motors as the thrusters, with 1 thruster for degrees of freedom heave, and 2 thrusters for degrees of freedom yaw and surge. ROV overall dimensions is length $475 \mathrm{~mm}$, width $325 \mathrm{~mm}$, height $270 \mathrm{~mm}$ and weighs $8.5 \mathrm{~kg}$. This ROV is controlled using a PS joystick connected using UTP cable. Three DC motors are used as drive generates 7 directions of movement can be accomplished by the ROV, i.e. up, down, forward, backward, turn right, turn left, and idle. Speed mode setting when forward movement on PWM $75 \% 0,037 \mathrm{~m} / \mathrm{s}, 90 \% 0.053 \mathrm{~m} / \mathrm{s}$ and $100 \% 0,071 \mathrm{~m} / \mathrm{s}$, while the reverse speed by $75 \% 0,034 \mathrm{~m} / \mathrm{s}, 90 \% 0.045 \mathrm{~m} / \mathrm{s}$ and $100 \% 0.059 \mathrm{~m} / \mathrm{s}$. Speed when the ROV moves up is $0,042 \mathrm{~m} / \mathrm{s}$, down $0.032 \mathrm{~m} / \mathrm{s}$, turn right 9 o/s and turn left $15 \mathrm{o} / \mathrm{s}$ set with fixed PWM value of $100 \%$. 


\section{References}

[1] Fauzi MN. Sistem Navigasi Pada Wahana Bawah Air Tanpa Awak. Final Project. Electronic Dept. PENS-ITS; 2009.

[2] Izwan MF. Control System Remotely Operated Vehicle (ROV). Master Thesis. Electrical-Electronics Engineering. Universiti Teknologi Malaysia; 2014.

[3] Suwarto R. Remotely Operated Underwater Vehicle. Final Project. Electrical Engineering Dept. Universitas Kristen Petra; 2006.

[4] Wakamenta YN. Perancangan dan Impelentasi Robot IUV-ROV (Integrated Underwater Vehicle) Sebagai Alat Bantu Survei Bawah Air. Final Project. Komputer Science Dept. Universitas Sumatera Utara; 2011.

[5] Ahmed YM, Yaakob O, Sun BK. Design of a New Low Cost ROV Vehicle. Jurnal Teknologi Universiti Teknologi Malaysia. 2014; 69(7): 2180-3722.

[6] Darwish FH, Atmeh GM, Hasan ZF. Design Analysis and Modeling of a General Aviation Aircraft. Jordan Journal of Mechanical and Industrial Engineering. 2012; 6(2): 1995-6665.

[7] Tehrani MH, Heidari M, Zakeri Y, Ghaisari J. Development, Depth Control And Stability Analysis Of An Underwater Remotely Operated Vehicle (ROV). In: 8th IEEE International Conference on Control and Automation. 2010.

[8] Kaharjito FA, Alimuddin, Wiryadinata R. Perancangan Robot Penjelajah dengan Sistem SKID Steering Menggunakan Telecommand sebagai Kendali Manual. In: The 2nd National Conference on Industrial Electric and Electronic 2012 (NCIEE). 2012.

[9] Wiryadinata R, Kaharjito FA, Pengujian Kehandalan Sistem Elektronis dan Teleceommand pada Robot Penjelajah. Journal TEKNOIN. 2012; 18(1).

[10] Adi AN. Antarmuka Joystick PlayStation dengan Mikrokontroler AVR Menggunakan CVAVR. Mecatronic Lab. Mechanical Engineering Dept., Universitas Islam Indonesia, 2009.

[11] Christ RD, Wernli SrRL. The ROV Manual: A User Guide for Observation Class Remotely Operated Vehicles. Oxford: Elsevier. 2007.

[12] Wiryadinata R, Wahyunggoro O, Widada W, Sunarno, Santoso MI. Modification of Strapdown Inertial Navigation System Algorithm for Rocket Flight Test. Journal Theoretical and Applied Information Technology. 2015; 72(2).

[13] Wang W. Autonomous Control of a Differential Thrust Micro ROV. Master Thesis, Mechanical Engineering, University of Waterloo, 2006. 